\title{
POLISH CONTRIBUTION TO SPACE RESEARCH
}

\author{
Piotr WOLAŃSKI \\ Institute of Aviation, Warsaw, Poland
}

Source of support: Own sources

Author's address: P. Wolański, Institute of Aviation, Warsaw, Poland, e-mail: wolanski@itc.pw.edu.pl

Background: A short historical description of Polish contribution to space research is given. Polish activities in the field of space exploration, such as instruments designed and built in Poland and placed on board of rockets, satellites and space probes during the last 60 years are described. Contributions of the Space Research Center of the Polish Academy of Sciences (SRC of PAS), Institute of Aviation (IA), Military Institute of Aviation Medicine (MIAM) and others are presented. Also a discussion on new directions in education, scientific research and industrial development is discussed.

Keywords: space flight, space research, rocket, satelitte

\section{INTRODUCTION}

Space has always excited people. In the past Sun, Moon and stars were the subject of religious cults and fascinations, but as time went by, more mysteries of our universe were explained and scientists unveiled many previously mysterious phenomena. In this activity Poles have played a very important role. Nicolaus Copernicus was the first who understood planetary motions in our Solar System, Johannes Hevelius created the first moon map, while Kazimierz Siemienowicz [1] proposed stabilization of rocket with aerodynamic fins, multistage rocket and rocket clusters (Fig. 1). Later on general Józef Bem made further improvement of a rocket. In XIX century Ignacy Łukasiewicz developed a method of production of kerosene while Karol Stanisław Olszewski and Zygmunt Wróblewski were the first to obtain liquid oxygen. Not many people knows that ideas of Siemienowicz, as well as discoveries of Łukasiewicz, Olszewski and Wróblewski are used in many space rockets, including the one that was used to launch the first Sputnik. Kerosene and liquid oxygen from the be-

Figures: 7 • References: 3 • Full-text PDF: http://www.pjamp.com • Copyright C 2013 Polish Aviation Medicine Society, ul. Krasińskiego 54/56, 01-755 Warsaw, license WIML • Indexation: Index Copernicus, Polish Ministry of Science and Higher Education 
ginning of the Space Era are the most commonly used rocket propellants. At the beginning of the XX century Franciszek A. Uliński drew the project of Interplanetary Spaceship. In this paper Poland's contribution to space research and exploration over the last sixty years is briefly described.

\section{SPACE-RELATED NATIONAL ACTIVITIES}

Even before the launch of the first Sputnik in 1956, professor Kazimierz Zarankiewicz organized the Polish Astronautical Society (PAS). In 1958 UN Committee on Peaceful Uses of Outer Space (COPUOS) was created and Poland was among the first members of that significant Committee. We also participated from the very beginning in the work of the Committee of Space Research (COSPAR). Professor Włodzimierz Zonn, the first Polish representative to those Committees, organized in Warsaw two very important meetings of those organizations: in 1963 COSPAR Congress and in 1964 Congress of the International Astronautical Federation (IAF). In 1968, Polish Academy of Sciences created Committee for Peaceful Uses of Outer Space which since 1990 has worked under the name of Committee on Space Research of the Polish Academy of Sciences. The Committee is affiliated with the Presidium and consists of 35 members nominated by the President of the Polish Academy of Sciences. It has five Sections: Astronautics and Space Technology, Astrobiology and Space Medicine, Physics of outer Space, Satellite's Geodesy and Teledetection. Committee represents Poland in UN COPUOS, COSPAR and IAF.

In the seventies of the last century, spacerelated scientific activity of Poland was basically confined to Interkosmos program coordinated by the Soviet Union [3]. Under that program, many instruments were developed and constructed in Poland and later launched into space on board of the Soviet rockets. The first Polish instruments were launched into space aboard the Vertical rockets. They were designed to study the Sun in the X-ray spectrum. Those instruments were designed by Professor Jan Mergentaler from Wrocław.

Another important instrument which was launched into orbit on board of "Interkosmos-9 Kopernik 500" was radio-spectrograph RS-500 K (Fig. 2). That instrument was designed and built in the IA by Zygmunt Krawczyk, MS PhD, under scientific supervision of Professor Jan Hanasz from Nicolaus Copernicus University in Toruń.

In 1965-1973, under the direction of Jacek Walczewski and Jerzy Haraźny from the National Institute of Weather and Water Management in IA, about two hundred "Meteor" rockets were built and launched [23]. Those rockets were designed to study the upper layers of the atmosphere at altitudes between $30 \mathrm{~km}$ and $100 \mathrm{~km}$ (Fig. 3).

Also in 1976, the Institute of Geodesy and Cartography created Remote Sensing Center "OPOLIS". Activities of the Center encompassed a broad
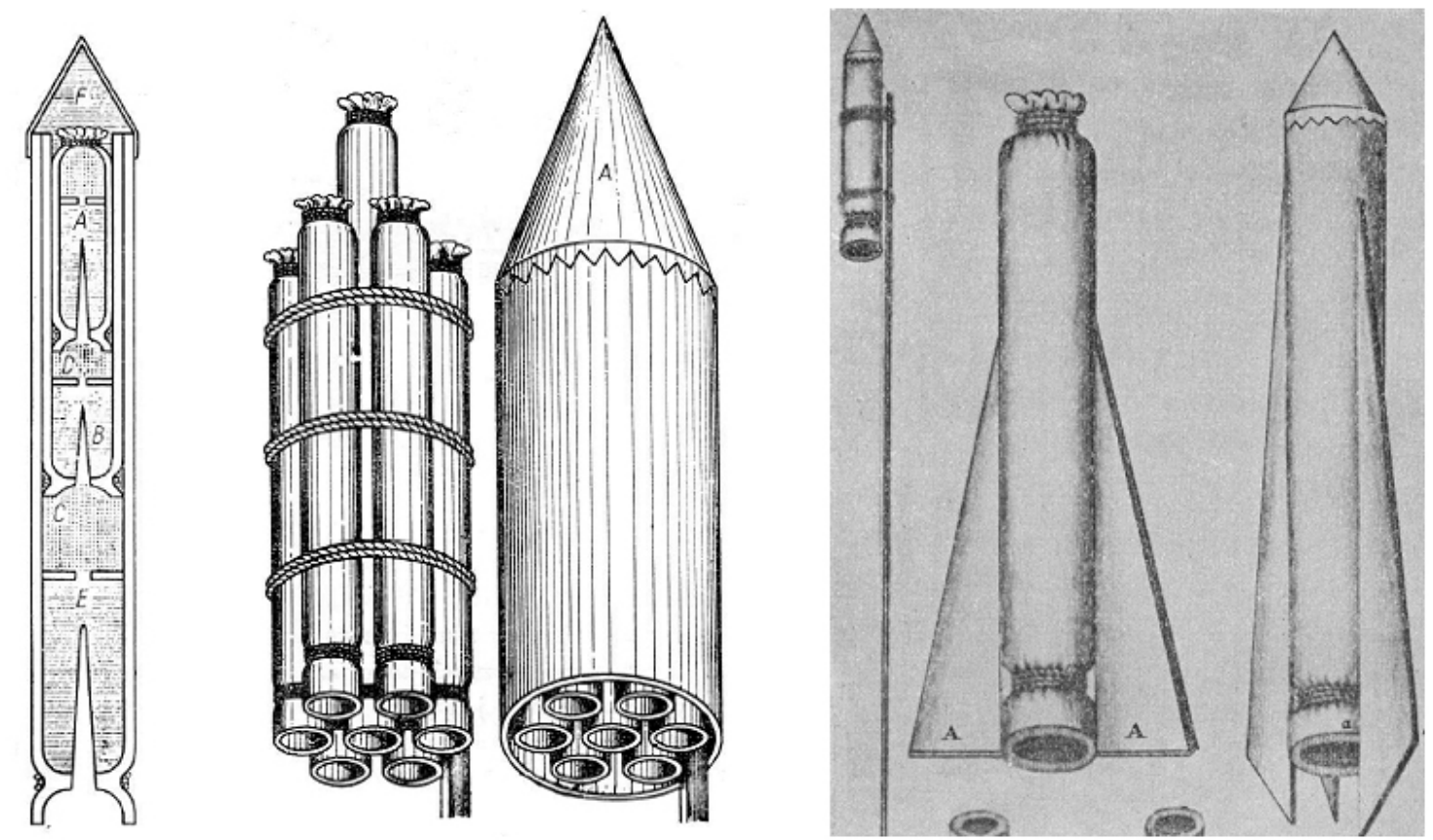

Fig.1. The ideas of Kazimierz Siemienowicz (1650). Multistage rocket, rocket cluster and stabilization of rocket by aerodynamics fins. 


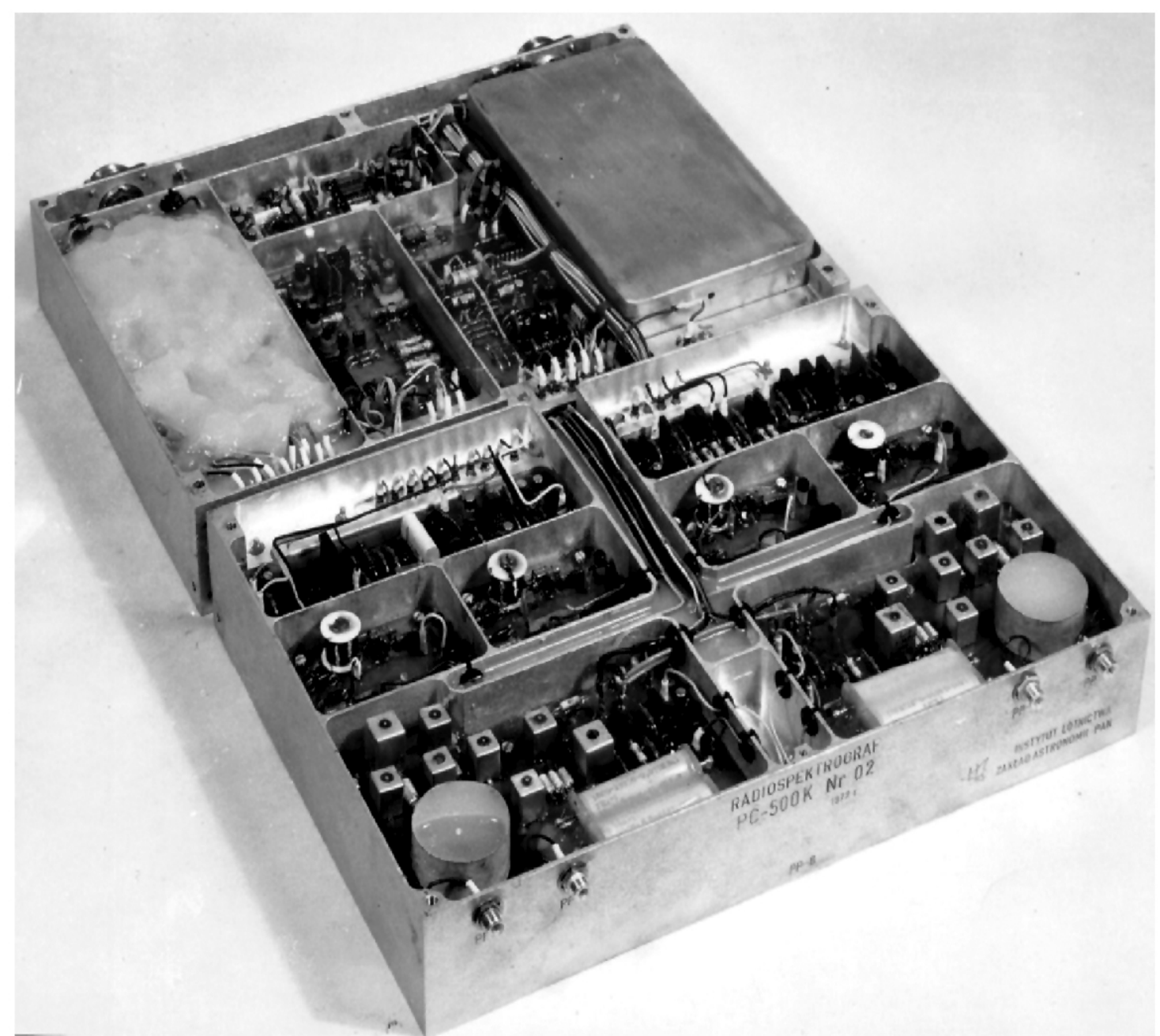

Fig. 2. Radiospectrograph RS-500 K, Polish instrument on board of the "Interkosmos-9" satellite.

range of research related to the use of various satellite images and products for agriculture, which included: forecasting of yield, drought detection, crop recognition and crop condition assessment, estimates of heat and carbon fluxes between surface and air, detection of soil moisture changes in wetland areas, hydrological aspects, bioenergy, forests, natural hazards: floods, forest fires and landslides as well as land cover and land cover changes.

In February 1977, SRC of PAS was established. This Institute is engaged in a wide range of research topics including: physics of the Sun (a division in Wrocław), study of planets and small Solar System bodies, interplanetary space physics and astrophysics, plasma physics, planetary geodesy and geodynamics (a division in Borowiec).

In 1978, on board of the Soyuz-30, Mirosław Hermaszewski, the only Polish cosmonaut, was launched into space with a Russian cosmonaut Piotr Klimuk (Fig. 4). Their spaceship docked later to the Salyut-6 space station. During an 8-day mis- sion, 11 experiments were conducted. Medical experiments conducted during that flight were prepared at MIAM under the supervision of professor Stanisław Barański. Technological experiment "Syrena" ("Siren"), devoted to material study under microgravity conditions, was prepared by the Institute of Physics of the Polish Academy of Sciences under the supervision of professor Robert Gałązka. It should be also mentioned that the selection of candidates for a cosmonaut was conducted at MIAM. For a long time in the 1970s and 1980s that Institute was involved in intensive research in the field of medical aspects of space flights, astrobiology and aeromedicine, including psychological aspects of long-term space flights. Also for a long time, the activities of PAS were closely connected to that Institute.

After the change of the political system in Poland, Polish space activities were widened to include international cooperation with ESA members, NASA as well as with India, Japan, China and other countries. Instruments designed and built 


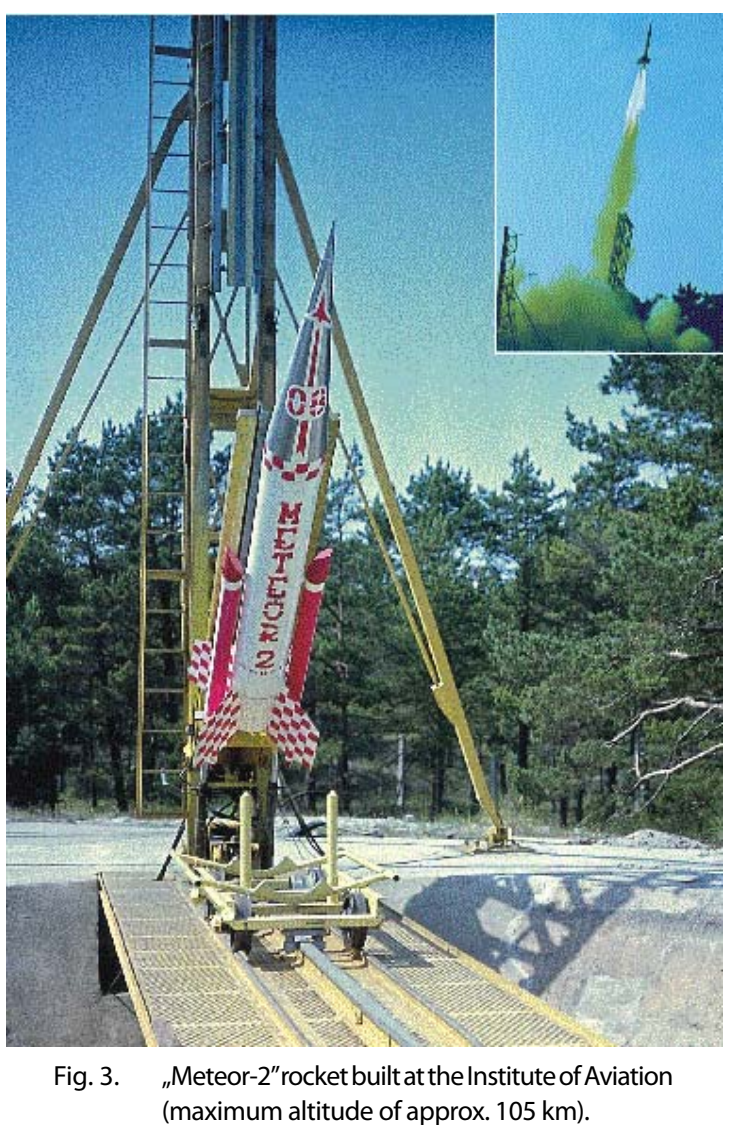

in Poland were present in many international missions, such as: CASSINI, MARS EXPRESS and VENUS EXPRESS. In January 2005, the space probe HUYGENS landed on the Saturn's moon Titan with instruments designed to study thermal properties of the surface of that moon. Those instruments were built by SRC of PAS. Also a part of instruments aboard HERSCHEL astrophysical observatory designed to study evolution of the Universe were built at SRC of PAS. On board of the ROSETTA spacecraft, which will land next year on Churyumov-Gerasimenko comet, there will be a Polish penetrator MUPUS (MUIti PUrpose Sensors for surface and subsurface science) built at SRC of PAS. Altogether, owing to involvement in space exploration, more than 70 instruments built in Poland were launched into space.

GPS, GNSS and other satellites have been used in Poland for geodesy and scientific programs. Moreover, Poland participates in the European Geodesy Reference System EUREF (EUropean REference Frame) and has 100 reference stations for the network. Poland is a full member of EUMETSAT. Our link to EUMETSAT is the Institute of Meteorology and Water Management Ground Satellite Centre in Kraków which has been continuously working on and receiving pictures as well as other information from meteorological satellites for more than 45 years.

Before the end of the last century, Poland signed cooperation agreements with ESA which resulted initially in PECS agreement and later on in a full accession to ESA. That was possible owing to a strong and continuous support of the Polish Government and especially the Ministry of Economy, the Ministry of Science and Higher Education, the Ministry of Foreign Affairs, the Committee of Space of the Polish Academy of Sciences and the Parliamentary Group for Space Research. At the beginning of November 2012 both chambers of the Polish Parliament accepted unanimously the ratification of our accession to ESA and as a result Poland became the 20th full member of ESA on 19 November 2012.

The education of space science is constantly evolving in Poland. This includes special educational programs for primary and high schools. Special programs dedicated to space education exist at the Warsaw University of Technology and other universities. ESA granted special projects for supporting educational activities of students at the Warsaw University of Technology and Wrocław University of Technology. Students from the Warsaw University of Technology from the Astronautical Group were involved in many projects related to space activities such as: microgravity flights, Mars Rover Competition with Skarabeusz, REXUS/BEXUS, European students' satellite SSETI Express, Yes-2, ESEO, ESMO. With the help of SRC of PAS, they also built the first Polish satellite PWSat, which was launched into orbit on 13 February 2012 by VEGA. Currently, the students from the Warsaw University of Technology are involved in many other projects such as development of experimental two-stage rockets, second cubesat "PW-Sat-2" as well as NASA Fourth Annual Lunabotics Mining Competition, in the project dealing with design of a digging robot called "Huzar".

In 2005, a degree of Msc in "Aerospace" was established by the Ministry of Science and Higher Education. Since that time, the number of students interested in space education has been continuously growing in Poland and there is a necessity to create a new course of studies i.e. "space technology".

The Polish space industry companies are beginning to cooperate in the field of development. In 2012, companies in Poland established the first Polish Space Industry Association. Now it includes more than 25 companies but many other are considering membership. 


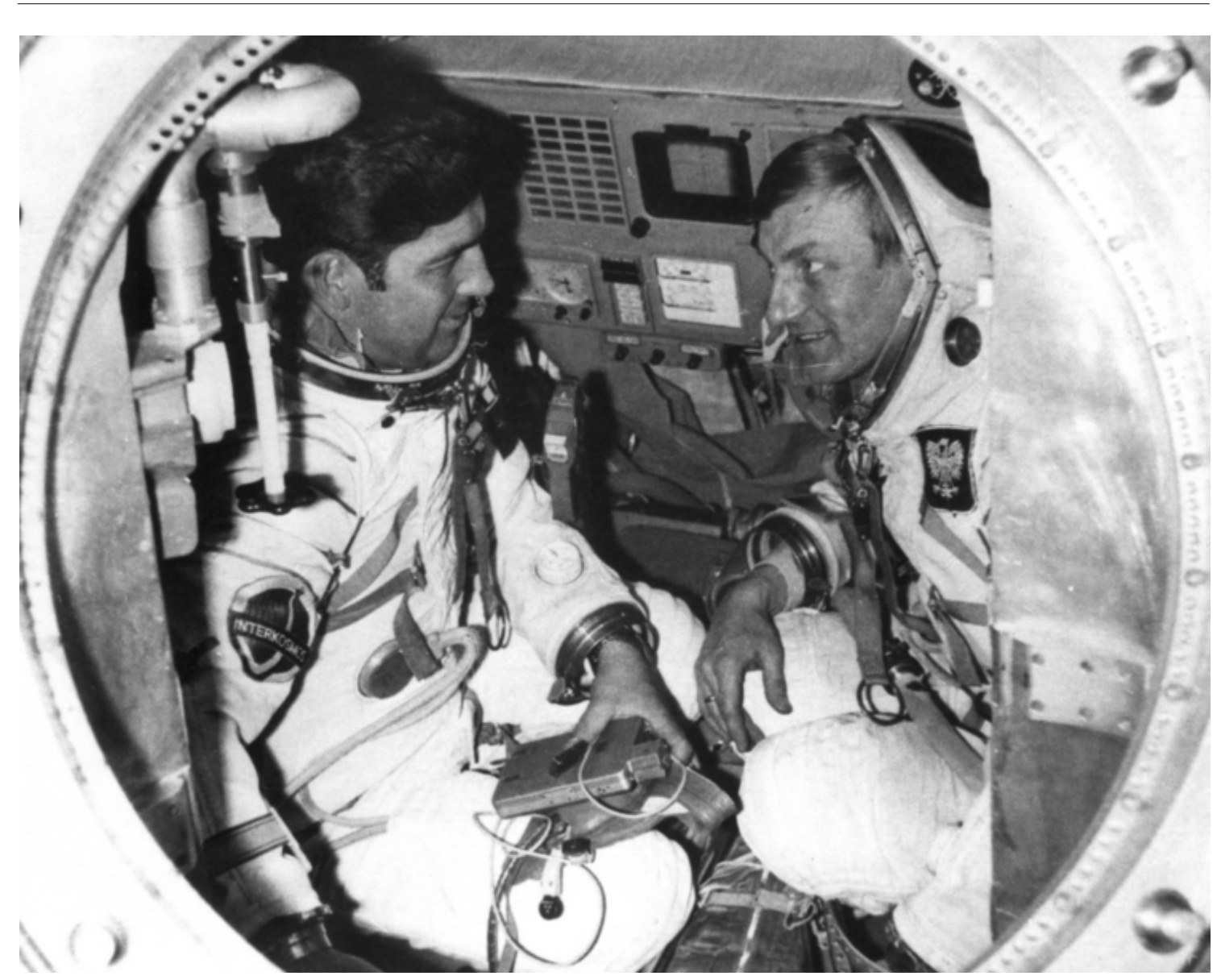

Fig. 4. Piotr Klimuk and Mirosław Hermaszewski during preparation for space flight.

In November 2013, the Polish scientific satellite "LEM", named after a famous Polish science fiction writer, is to be launched into space. The satellite is a part of a constellation constructed jointly by Austria, Canada and Poland. This constellation, called "BRITE" is designed to study the dynamics of bright stars (Fig. 5). The next Polish satellite in the "BRITE" constellation is named "HEWELIUSZ", after the famous Polish astronomer, and will be launched soon on board of the Chinese rocket Long March 3C. Both Polish satellites of "BRITE" constellation were built by SRC of PAS.

In the IA, similarly as in the 1970s, space technology is gaining momentum. A unique technology of purifying hydrogen peroxide to approx. 98\% of purity was developed (Fig. 6). This technology is unique in Europe and Poland and soon IA should be the largest producer of such substances for space technology and chemical industry. Moreover, in this institute, green propellants for rocket propulsion were successfully tested, including hybrid and bipropellant rocket engine for satellite propulsion. It is also possible to develop a rocket launcher for small satellites, as Romania is doing, or to joint Romania and other counties in such undertakings. Since the rapid development of miniaturization technology, the creation of mini-, microand nano-satellites with similar performance levels as the large ones currently in service, will soon become a reality. Additionally, they will become less expensive. Therefore, building a small satellite launcher will be necessary, especially if Europe wants to be an independent partner in space exploration (Fig. 7). We cannot lose the chance to be independent in having access to space. Without access to space no one can build a strong space program and a strong space industry.

It is now discussed to establish a Polish Space Agency, which as in other countries would be responsible for management and coordination of Polish space activities and represent Polish government in ESA. In my opinion, such a body is needed and would further boost space technology as well as enhance the competitiveness of Polish space industry and academia on the international market. 


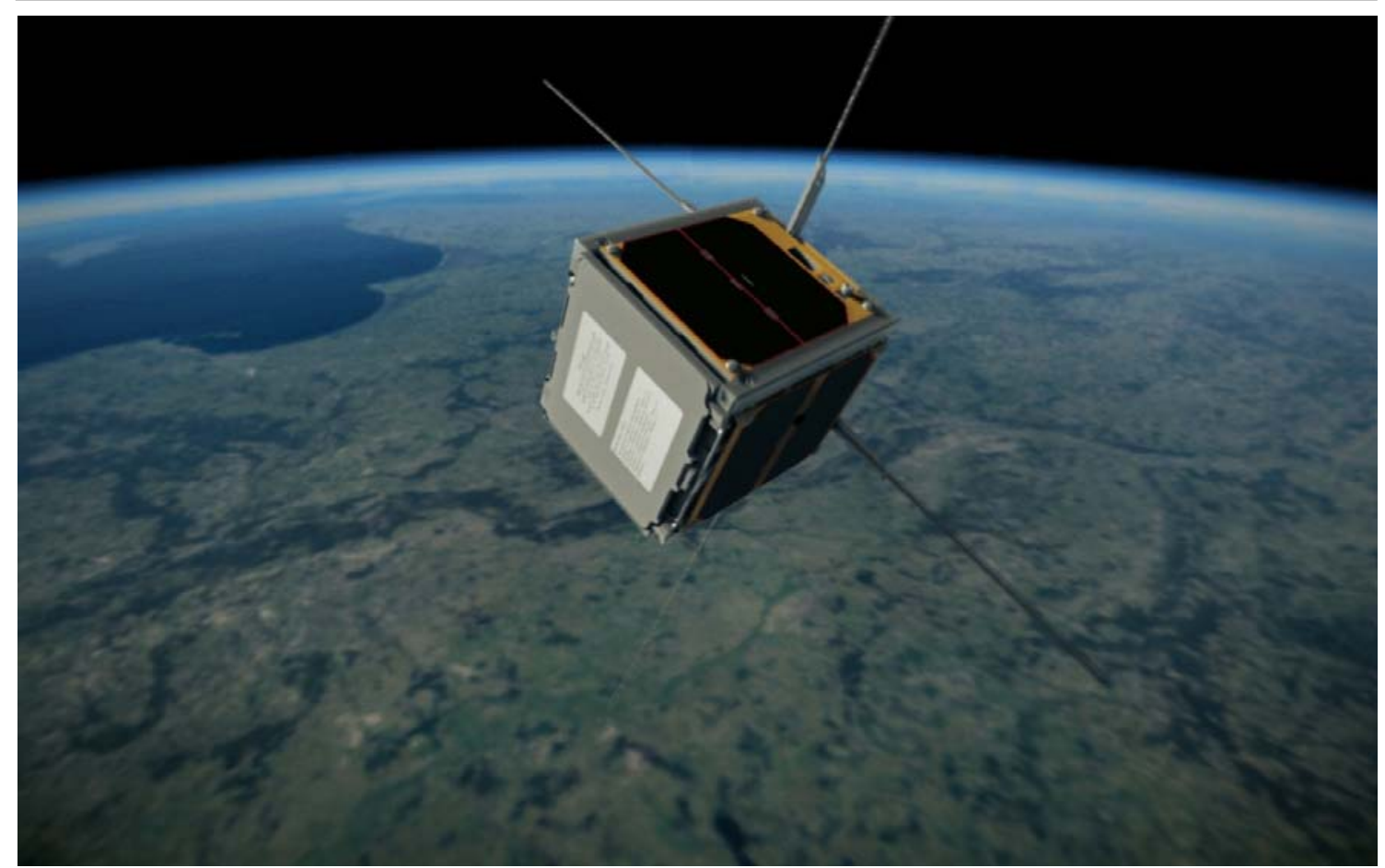

Image by Paweł Sańczyk.

Fig. 5. The first Polish Satellite PW-Sat.
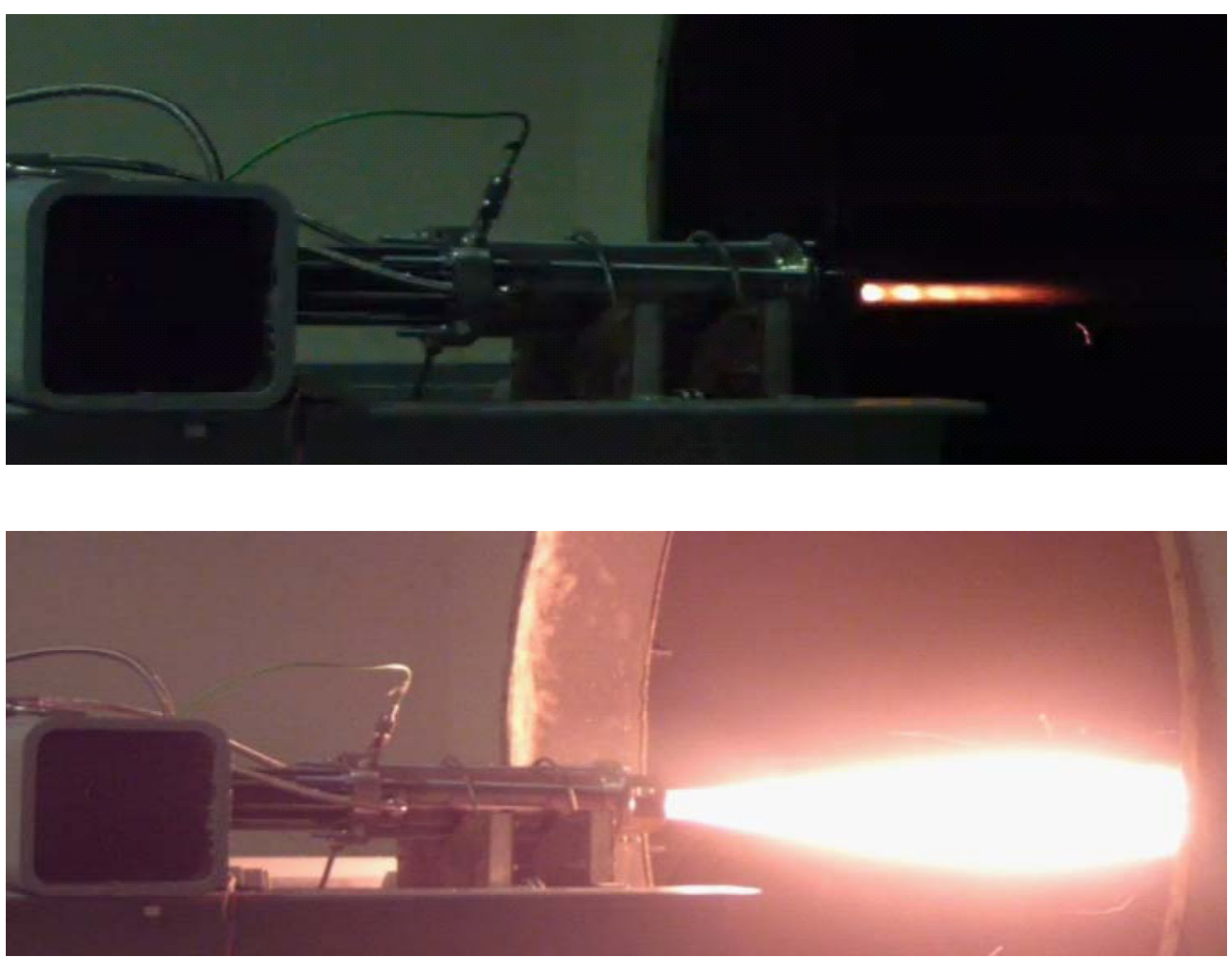

Fig. 6. Rocket engine tests at the Institute of Aviation in Warsaw. a) bipropellant engine $\left(98 \% \mathrm{H}_{2} \mathrm{O}_{2}+\right.$ kerosene), b) hybrid rocket $\left(98 \% \mathrm{H}_{2} \mathrm{O}_{2}+\mathrm{HTPB}\right)$. 

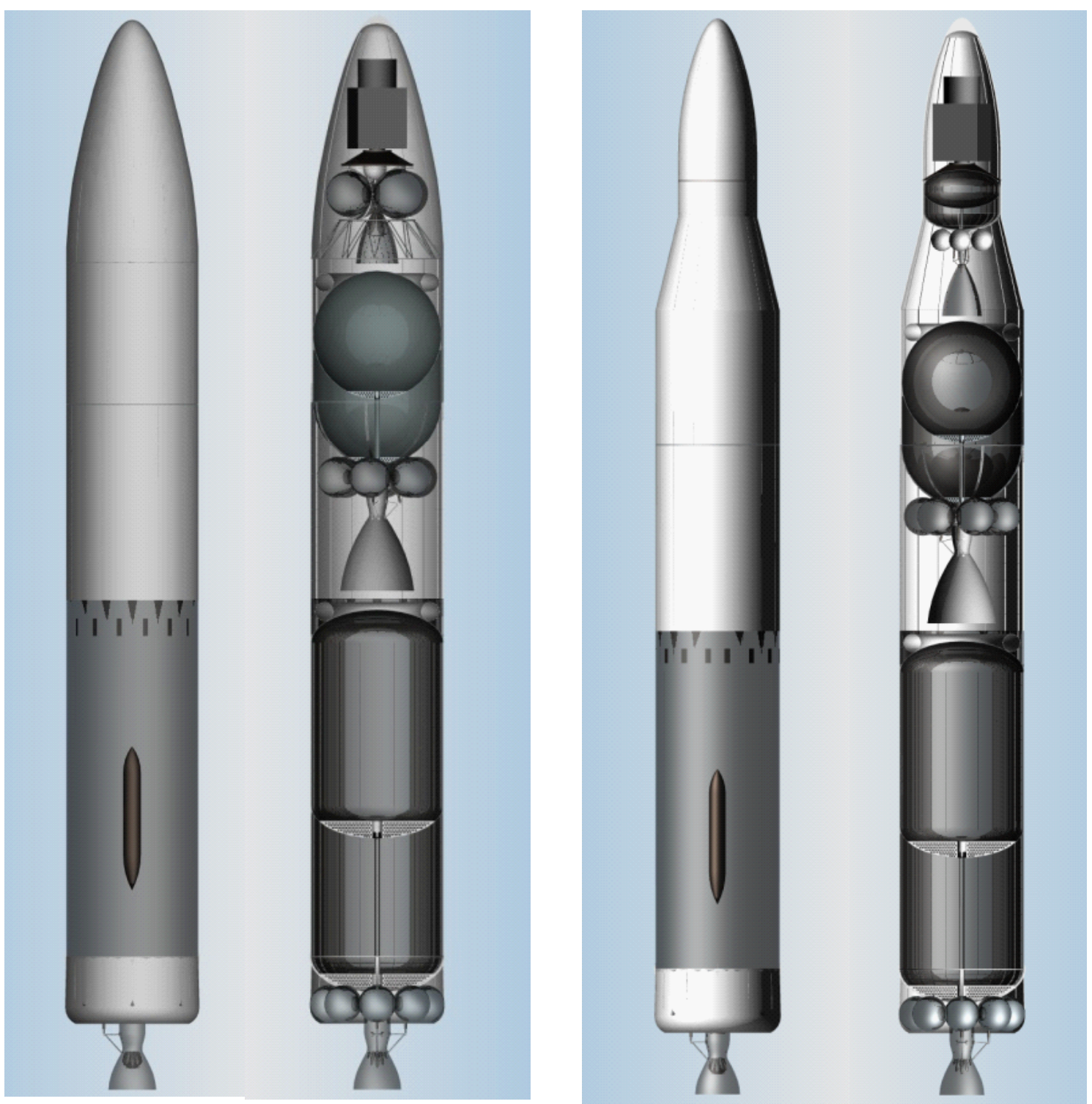

Fig. 7. Two different configurations of the rocket for launching small satellites into SSO studied at the Space Technology Division of the Institute of Aviation in Warsaw.

\section{CONCLUSIONS}

Poland has always been active in the field of space research, but recently these activities have accelerated. This is mainly due to our recent accession to the ESA. The accession should stimulate activities in all possible aspects, but basically in research and technology development. To date, our biggest contribution to space research has focused on scientific aspects of space exploration. However, to secure the highest returns from investments in space, our activities should be redirected towards technological aspects. The biggest return of our money spent on space will be from development of new technologies. Poland should be more actively involved in two biggest European space programs, such as Galileo and GMES, but also develop small satellites. If we invest only in space science, our return from the investments will be much lower than in case of the investments in new space technologies. Poland should also invest in the development of new launches, similarly to Romania. When examining all investments in space technology in the world, we may find out that only slightly more than $10 \%$ is allocated to purely scientific missions and the rest is spent on different technological and application aspects of space exploration. 


\section{AUTHORS' DECLARATION:}

Study Design: Piotr Wolański; Data Collection: Piotr Wolański; Manuscript Preparation: Piotr Wolański; Funds Collection: Piotr Wolański. The Author declares that there is no conflict of interest.

\section{REFERENCES}

1. Siemienowicz, K. (1650) Artis Magnae Artilleriae pars prima. Amsterdam.

2. Struzik, P. (2008) Satelity meteorologiczne od 40 lat w służbie IMGW. Nauka. 4. 35-42.

3. Wolański, P., Banaszkiewicz, M., Kłos, Z., Ziółkowski, J., Zdziarski, A. (2008) Udział Polski w badaniach kosmicznych. Nauka. 3. 65-79.

Cite this article as: Wolański P: Polish Contribution to Space Research. Pol J Aviat Med Psychol, 2013; 19(3): 45-52. 